Article

\title{
The Use of Soundscapes to Monitor Fish Communities: Meaningful Graphical Representations Differ with Acoustic Environment
}

\author{
Rita Carriço ${ }^{1,2, *}$, Mónica A. Silva ${ }^{1,3}{ }^{\mathbb{D}}$, Manuel Vieira ${ }^{2,4,5}$, Pedro Afonso ${ }^{1}$, Gui M. Menezes ${ }^{1}$, \\ Paulo J. Fonseca ${ }^{4,5}$ and Maria Clara P. Amorim ${ }^{2,4}$ \\ 1 Institute of Marine Research (IMAR), OKEANOS—R\&D Centre, University of the Azores, \\ 9900-138 Horta, Portugal; monica.silva.imar@gmail.com (M.A.S.); pafonsopim@gmail.com (P.A.); \\ gui.mm.menezes@uac.pt (G.M.M.) \\ 2 Marine and Environmental Sciences Centre (MARE), ISPA-Instituto Universitário, 1149-041 Lisboa, Portugal; \\ manuel_1990_v@hotmail.com (M.V.); mcamorim@fc.ul.pt (M.C.P.A.) \\ 3 Biology Department, Woods Hole Oceanographic Institution, Woods Hole, MA 02543, USA \\ 4 Departamento de Biologia Animal, Faculdade de Ciências, Universidade de Lisboa, Campo Grande, \\ 1749-016 Lisboa, Portugal; pjfonseca@fc.ul.pt \\ 5 Centre for Ecology, Evolution and Environmental Changes (cE3c), Faculdade de Ciências, \\ Universidade de Lisboa, Campo Grande, 1749-016 Lisboa, Portugal \\ * Correspondence: ritcarrico@gmail.com
}

Received: 30 April 2020; Accepted: 11 June 2020; Published: 13 June 2020

check for updates

\begin{abstract}
Many marine animals produce sounds in several phases of their life cycles, either actively or as a byproduct of their activities, such as during mate attraction or when moving. Recent studies of underwater soundscapes have proved passive acoustic monitoring to be a cost-effective, non-invasive tool to understand ecological processes, especially when sampling in adverse conditions or at great depth. Four days of sound recordings at three seamounts from the Azorean archipelago were examined to assess the suitability of different sound graphical representations to characterize different acoustic environments that contrast in the contribution of vocal fish communities. Long-term spectrograms, sound pressure level, spectral probability densities and the Acoustic Complexity Index (ACI) were computed for two shallow seamounts (Formigas and Princesa Alice, c. $35 \mathrm{~m}$ ) and one deep seamount (Condor, $190 \mathrm{~m}$ ) using graphics with different time spans. Only in Formigas, which presented the highest occurrence of fish sounds, was it possible to observe temporal patterns of fish vocal activity in the graphical representations. We highlight that habitats with a higher diversity and abundance of sounds are the most suitable targets for these methods, while in locations with a low prevalence of fish sounds a combination of several methods would be recommended.
\end{abstract}

Keywords: acoustic ecology; passive acoustic monitoring; soundscapes; fish sounds; Northeast Atlantic; Azores

\section{Introduction}

In the marine environment, sound is a more efficient source of information than vision, touch, taste or smell. Sound provides fast (around five times faster than in air), long-distance information to marine animals during day and night [1-3]. Indeed, many marine species, including fish, use sound to navigate, select habitats, detect predators and preys, and to communicate [4-9]. The acoustic scene (or soundscape) that encompasses biotic, abiotic and manmade sounds is explored by animals as a source of information and may reveal biodiversity, ecosystem dynamics and ecological processes, and habitat health [10-13]. The urgent need to assess and monitor marine biodiversity has led humans 
to explore the information within soundscapes, which has driven significant advances in passive acoustic monitoring (PAM) and soundscape analysis [13]. PAM allows cost-effective, long-term studies with a negligible impact in the biota while revealing information on acoustic sources, their amplitudes, the interaction between the different sources and how marine species may interpret and react to sounds [14].

The biogenic component of soundscapes is mostly related to cetacean, fish and invertebrate sounds, and its study can bring insights about the community composition of vocal/acoustic species $[10,15,16]$. PAM can be particularly useful to monitor populations over long periods of time, detect reproductive aggregations, or follow spatiotemporal activities of soniferous species [17-19]. For example, Caiger et al. [19] used PAM to detect spawning activity trends of Atlantic cod over ten consecutive winter spawning seasons in Massachusetts Bay (USA), providing valuable insights into its spawning ecology, conservation and fishery managers. The Atlantic cod, like many other fish species, form dense breeding vocal aggregations often showing site-fidelity, accounting for a major component of soundscapes, especially at the lower frequency range $(<2 \mathrm{kHz})$ explored by fishes [19-23].

Due to the presence and prevalence of different communities, different habitats have distinct soundscapes that are dynamic in space and time [10,24-26]. To extract information from long-term soundscape recordings and capture this dynamic, a wide variety of data reduction (e.g., acoustic indices) and data visualization techniques (e.g., long-term sound pressure level representations, long-term spectrograms, power spectral density percentiles) have been used [12,13,25]. Data visualization methods may be particularly useful to target particular communities or species as they enable rapidly scanning for patterns in the soundscape, and have been increasingly applied to aquatic environments, mainly focusing on marine mammals but also on fishes [23,27]. In turn, data reduction, namely acoustic indices, can provide important information on biodiversity, e.g., the Acoustic Complexity Index (ACI), the Acoustic Entropy Index, or Acoustic Richness [12,28,29]. Nevertheless, soundscape data reduction and visualization remain a significant research area [12,30,31], and whether the same methods apply to, and allow for, comparisons of different ecosystems remain to be ascertained. For example, a given metric or resolution for data visualization may be suitable for a community that is rich in frequency-modulated biological sound events (e.g., cetacean sounds) but inadequate for one dominated by short broadband sounds (such as the clicks of invertebrates), or with few relatively narrow-band low frequency sounds, such as those of fishes [12]. Finding the best approaches for typical communities is needed and especially important when the standardization of marine soundscape measurements is warranted [13].

Despite recent advances in marine soundscape analysis [6,11,14,24,32,33], significant gaps still need to be addressed, including the identification of vocal fish species and their periods of vocal activity, as acoustic indices characterize mostly vocal species during key phases of their lives $[10,19,20]$. In addition, there is a need to standardize marine soundscape measurements and refine soundscape exploration and visualization techniques [12-14].

Here, we aim to characterize the acoustic environment of shallow and deeper seamounts from the Azorean archipelago, focusing on the contribution of vocal fish to the overall soundscape, and to investigate the best visualization methods and acoustic metrics to detect fish communities that may vary in their acoustic presence across different locations and habitats. We highlight the importance of the vocal fish communities to marine soundscapes and put into evidence that long-term visualization methods may only be informative in habitats with a high acoustic abundance and diversity, such as shallow water seamounts. In contrast, at locations where biological sounds are less frequent, visualization methods should have a higher temporal resolution and be complemented with other methods, such as automatic detection or a combination of acoustic indices. We propose that soundscape analysis can be an effective tool for monitoring biodiversity and for conservation efforts but needs to be adjusted to the particularities of the sampled ecosystems. 


\section{Materials and Methods}

\subsection{Study Site}

This study was conducted in the Azorean archipelago. The Azores are located in the Northeast Atlantic, about $1600 \mathrm{~km}$ from Portugal. The archipelago comprises nine islands and several seamounts of volcanic origin. Seamounts are important biodiversity hotspots for marine life harboring several fish species [34]. Sound recordings from three seamounts were investigated: Condor (depth, $190 \mathrm{~m}$ ), located at $17 \mathrm{~km}$ from Faial Island, was established as a protected area in June of 2010, when most fisheries were forbidden [35]. Princesa Alice (depth, $36 \mathrm{~m}$ ) is located at $83 \mathrm{~km}$ from Faial Island, and until 2016 it had no protection status. Formigas (depth, $35 \mathrm{~m}$ ) is located at $55 \mathrm{~km}$ from Santa Maria Island and has been classified as a natural reserve since 1988 [36] (Figure 1).

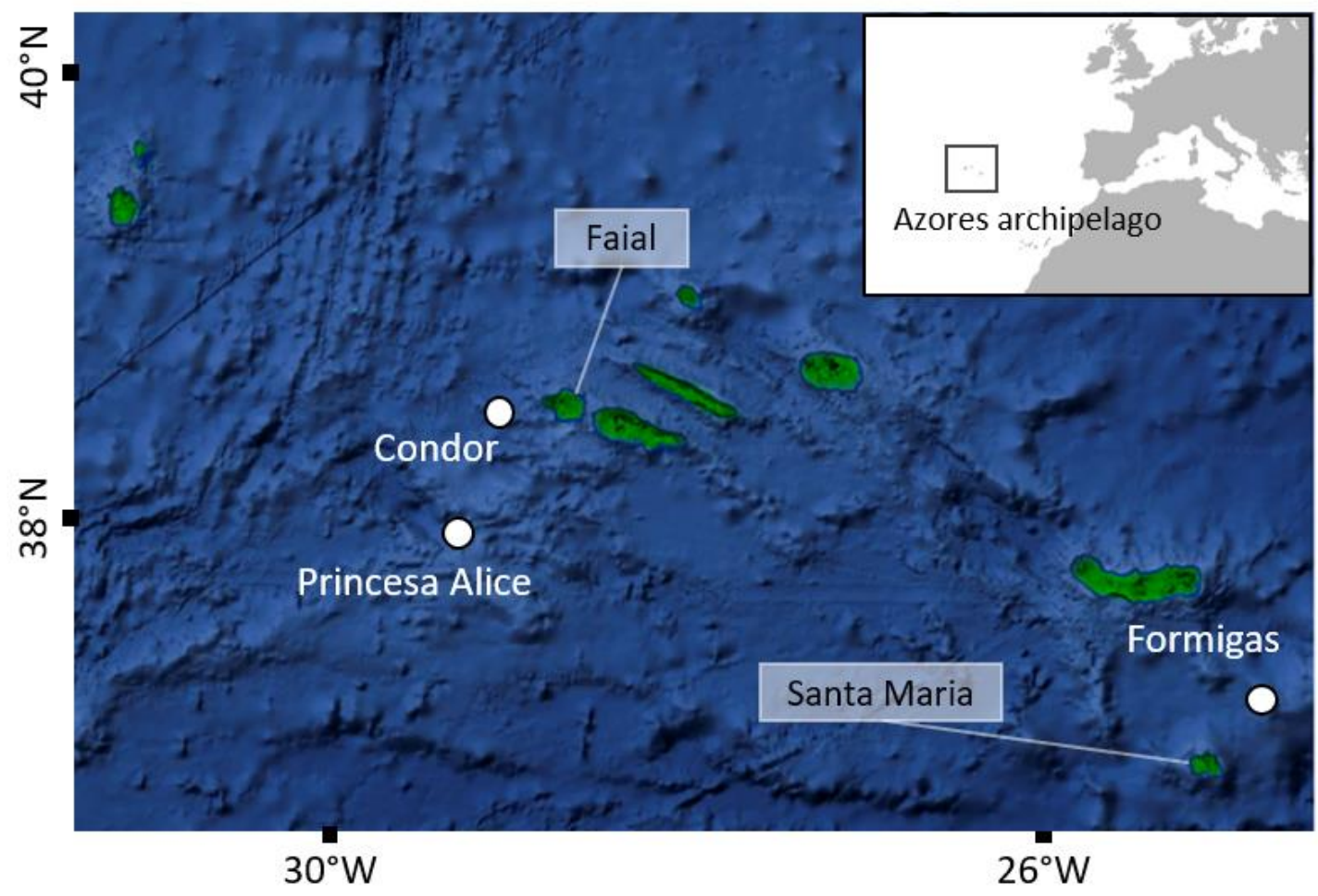

Figure 1. Location of the deployment of the Ecological Acoustic Recorders (EARs) in three seamounts of the Azorean archipelago (white dots).

\subsection{Acoustic Recordings}

Ecological Acoustic Recorders (EARs) [37,38] were deployed in three seamounts, Condor, Princesa Alice and Formigas, to obtain long-term recordings of the soundscape of these marine ecosystems (Figure 1) [39]. In Condor, the hydrophone was suspended at about 8-10 $\mathrm{m}$ from the sea bed with a floating device, while in Princesa Alice and Formigas both EARs were deployed on the sea bed by scuba-diving.

The EAR is an autonomous system that consists of a Sensor Technology SQ26-01 hydrophone with a response sensitivity of $-193.14 /-194.17 \mathrm{~dB}$ re $1 \mathrm{~V} / \mu \mathrm{Pa}$ (with some inter-deployments variation), with a frequency response within $\pm 1.5 \mathrm{~dB}$ in the range $1 \mathrm{~Hz}$ to $28 \mathrm{kHz}$. A Burr-Brown ADS8344 A/D converter was used with a zero-to-peak voltage of $1.25 \mathrm{~V}$, and a total system gain of $47.5 \mathrm{~dB}$ re $1 \mu \mathrm{Pa}$. Sounds were recorded in Formigas for 30 s every 600 s; in Princesa Alice and Condor for 90 s every $900 \mathrm{~s}$. The recordings were down-sampled to $8 \mathrm{kHz}$ to improve processing speed and search for fish sounds in spectrograms up to $4 \mathrm{kHz}$. 


\subsection{Data Analysis}

For the analysis, we considered recordings made during June 2010, one of the months where greater vocal activity would be expected $[40,41]$. Since we could not examine all the available recordings, to maximize the probability of selecting recording days with more animal sounds the Acoustic Complexity Index was calculated on the overall data set. A sub-sample of four June days exhibiting higher index values was then selected to be closely inspected. Notice that several authors reported a positive relation between the ACI and the number and diversity of fish sounds $[11,12,15]$, but the index is greatly dependent on the selected settings [12]. Therefore, from the available circa $36 \mathrm{~h}$, $15 \mathrm{~h}$ and $72 \mathrm{~h}$ of recordings, we selected about $5 \mathrm{~h}, 10 \mathrm{~h}$ and $10 \mathrm{~h}$ at Formigas, Princesa Alice and Condor, respectively. Additionally, we also analyzed one day in November of 2008 ( $2.5 \mathrm{~h}$ ) with the highest abundance of fish sounds at Condor in the period of 2008 to 2012 [42] to highlight intra-site variability.

The ACI algorithm computes the difference between adjacent spectra for each frequency bin and sums these differences within each time clump-for details on the ACI computation see $[28,43]$. Because biological sounds are usually transient and/or with variable spectral features, higher values of $\mathrm{ACI}$ are expected to be associated with higher sound abundance and diversity [44]. In contrast, more continuous geophony and anthrophony sounds are usually represented by lower acoustic complexity values, although random geophonic noises or intermitting anthropic sounds may cause an increase in ACI values $[12,28]$. The ACI calculations were made for the frequency ranges most used by fish, $15-2000 \mathrm{~Hz}$ and $2000-4000 \mathrm{~Hz}$, using the WaveSurfer software and the plug-in SoundscapeMeter [43] (FFT window size: 512 , frequency resolution: $8 \mathrm{kHz}$, clump of the ACI algorithm: $0.5 \mathrm{~s}$, noise filter: 0 ).

Acoustical analyses to identify and quantify the number of occurrences of fish sound sequences (a set of several isolated sounds that arises in a repetitive and stereotyped pattern, including from 1 to several sounds, [23]), were conducted by manually scrolling through the recordings and inspecting visually and aurally the spectrograms with Adobe Audition 3.0 software, following Carriço et al. [23]. The sound sequences used are described in Carriço et al. [23]. A 4 day and a $24 \mathrm{~h}$ stacked long-duration spectrograms spanning 0-2000 Hz were created for each location with the software WaveSurfer (sampling rate: $8 \mathrm{kHz}$; FFT size: 512; window type: Hamming; 50\% overlap). The spectrogram size was set to 256 pixels in the vertical (frequency) axis, and 1800 or 7200 pixels ( $24 \mathrm{~h}$ and 4-day spectrograms, respectively) in the horizontal (time) axis. The spectrogram was computed with a traditional Sparse Fast Fourier Transform (SFFT) method, and with this temporal representation each pixel depicted the mean value of circa 18-38 time bins (depending on the duty cycle: Formigas with $72 \mathrm{~min}$ per day, and Condor and Princesa Alice with $144 \mathrm{~min}$ per day). The long-duration spectrograms were accompanied by detailed plots with the associated occurrences of the sound sequence types. The frequency range used for each sound sequence was in accordance with Carriço et al. [23]. The $24 \mathrm{~h}$ spectrogram was accompanied by plots of the variation of sound pressure level (SPL), computed for the same frequency range throughout the day and the variation of the Acoustic Complexity Index. The ACI values represent the average of all clumps for each track for the frequencies $15-2000 \mathrm{~Hz}$. The expanded spectrograms (sampling rate: $8 \mathrm{kHz}$; FFT size: 512; window size: 64 points; window type: Hamming, 50\% overlap) of the most important sound sequence types were also made for each location. Spectral Probability Density plots (SPD) were computed for the same four days to examine the energy distribution along the frequency. These were compared with the power spectra of some of the most abundant fish sounds at each location. The sound pressure level (SPL) and the Power Spectral Density (PSD) were computed and calibrated in the computing environment R [45], adapting the code available by Merchant et al. [46] (SPL: FFT 512, Hann window, 50\% overlap, average for each file; PSD: FFT 4096, Hann window, 50\% overlap, 1 s average). For each deployment, the correction factor for calibration was calculated using the hydrophone sensitivity, system gain and zero-to-peak voltage of the analog-to-digital converter. 


\section{Results}

The presence and diversity of fish sounds were tallied for the three seamounts by manual scrolling of a subsample of four days from June 2010. Formigas had the highest abundance of fish sounds, with $93 \%$ of the files ( $5 \mathrm{~h}$ of $30 \mathrm{~s}$ recordings every $600 \mathrm{~s}$ ) containing fish sounds, and presenting 15 sound sequence types in total. This was the only location exhibiting choruses. In Princesa Alice, the abundance of sounds was considerably lower, with sounds present in only $37 \%$ of the files (10 h of $90 \mathrm{~s}$ recordings every $900 \mathrm{~s}$ ) but with a slightly higher total number of sound sequence types (17). Condor presented the lowest abundance and diversity, with fish sounds in only $9 \%$ of the analyzed files (10 h of $90 \mathrm{~s}$ recordings every $900 \mathrm{~s}$ ) and five sound sequence types. The most prevalent sound sequences were \#1, \#5, \#10,\#12, \#15, and \#50 for Formigas; \#1, \#5, \#10, \#12, and \#15 for Princesa Alice and \#1,\#4,\#5; and \#10 for Condor. Less common sounds were categorized as "others". These sound sequences were identified and characterized in Carriço et al. [23].

A set of spectrograms with expanding time scales (showing 4 days, 24 h, 6 h, 90 s or $270 \mathrm{~s}$ and $2 \mathrm{~s}$ ), accompanied by plots with associated occurrences of sound sequence types (represented by their mean peak frequency), $24 \mathrm{~h}$ plots of sound pressure level (SPL) and ACI values are shown for Formigas (Figure 2), Princesa Alice (Figure 3) and Condor (Figure 4).

In the long-term spectrograms from Formigas (4 days and $24 \mathrm{~h}$, Figure $2 \mathrm{a}, \mathrm{b}$ ), a higher presence of fish sounds, namely \#12 and \#50, was noticeable in the night period (9 p.m. -6 a.m.), whereas other sound types seem to have a wider occurrence during day time (\#15, \#10, others). In the expanded spectrograms (6 h, $90 \mathrm{~s}$ and $2 \mathrm{~s}$, Figure 2c-e), there is more energy in the frequency band 50-1500 Hz, which is related to the occurrence of fish sounds. In Figure $2 \mathrm{e}$, some of the sound sequence types (\#12, \#15 and \#50) previously described in Carriço et al. [23] are depicted. Sound pressure level follows a similar trend to the spectrogram (Figure $2 b$, orange line), presenting higher values associated with the occurrence of fish sounds, but the same trend is not obvious for ACI levels (Figure 2b, grey line). Interestingly, in Formigas seamount, the sound sequence types distribution depicted below the spectrograms (Figure 2a-d) highlights a frequency partitioning of the acoustic environment where sound sequence \#50 seems to occupy the lower frequencies and with a distribution mostly at dusk and dawn. Sound sequence \#15 seems to be ubiquitous during the day but occupying intermediate frequencies. In contrast, sound sequence \#12 was mostly present at night and occupied the higher frequencies. Sound sequences \#1, \#5 and \#10 were much less abundant, and were recorded at different times of the day, overlapping their frequencies with other sound sequences present at lower frequencies (Figure 2a,b).

The long-term spectrograms for Princesa Alice presented a high between-day variability (Figure $3 a, b$ ) and did not show an obvious daily pattern, likely related with the lower number of fish sound sequences. Although there was an increase in the SPL values associated to the presence of some fish sounds, the general patterns were not so obvious. The ACI levels were higher than in Formigas and did not present any noticeable pattern. Only at the most expanded spectrograms (Figure 3c,d) fish sounds could be detected. The sound sequence occurrence presented a similar pattern to the one observed in Formigas, where sound sequence \#12 was mostly present at night, and sounds $\# 1, \# 5, \# 10$, \#15 and "others" had a more ubiquitous distribution throughout the day (Figure 3a,b).

In the Condor seamount, where the EAR was deployed much deeper (190 m, and at 8-10 m above the seafloor), and the total number of sound sequences was much lower than those recorded in shallow waters, the information collected from the long-term spectrograms was much less representative, being ineffective to demonstrate the presence of the fish vocalizations (Figure $4 a, b$ ). As observed for the other locations, sounds \#1 and \#5 were also recorded at different times of the day despite of their low representation and abundance (Figure 4). The SPL at Condor (Figure 4b) was more constant throughout the day than in the shallow seamounts, but it was nevertheless close to or even higher at some times of the day than at Princesa Alice. However, it was not possible to observe the expected SPL increase associated with the presence of fish sounds noticeable in the spectrograms. As in Princesa Alice, the ACI levels did not present any clear pattern. To highlight the intra-site variability, Figure $4 \mathrm{e}$ 
illustrates the diel variation of one day registered at a different year in Condor (2008), depicting a much higher abundance of sounds: 193 sound sequences recorded in the 2 November 2008 versus 31 sound sequences (daily mean, SD $=27.3$ ) recorded in the 4 days of June 2010. On this day (2008), fish sounds, dominated by the fish sound sequence \#1, were visible in the spectrogram in the frequencies mostly below $500 \mathrm{~Hz}$. There was also a marked presence of wind/waves, anthropogenic noise and some cetaceans.

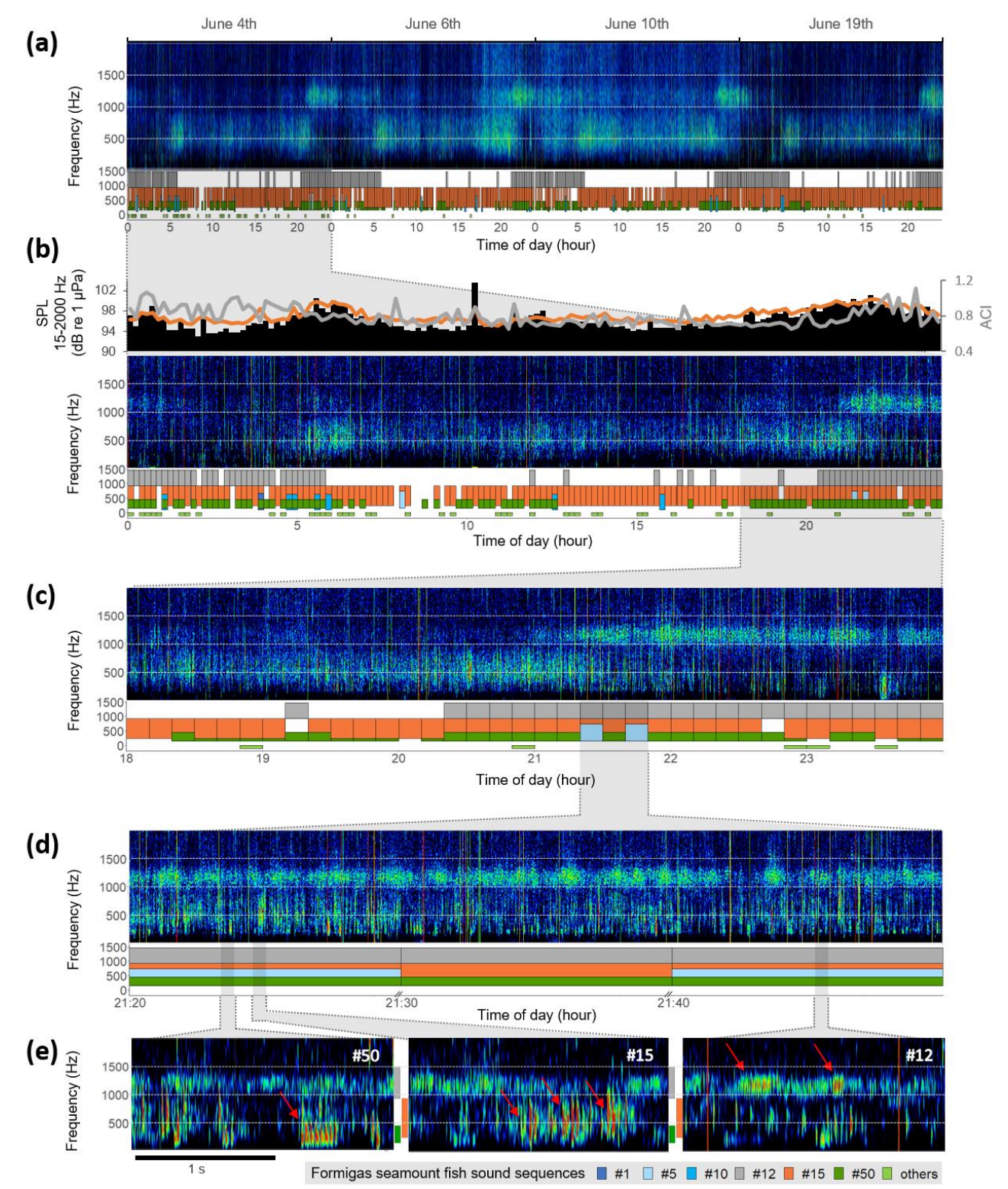

Figure 2. (a) Four-day long-term spectrogram from the Formigas seamount ( $35 \mathrm{~m}$ deep) with segments

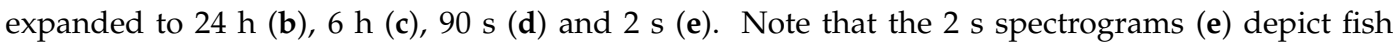
sound sequence types (\#12,\#15, \#50, reported in [23]). Sound acquisition was made $30 \mathrm{~s}$ every $600 \mathrm{~s}$. Under each spectrogram, the frequency range occupied by the most common fish sound sequences are represented. In (b), the sound pressure level (SPL) is presented for a $24 \mathrm{~h}$ period (4 June, black bars) for the frequency band $15-2000 \mathrm{~Hz}$, the average SPL considering the 4 days is depicted by the orange line, and the mean Acoustic Complexity Index (ACI) is also presented for the same frequency band by the grey line. Spectrogram settings (a-d): sampling frequency: $8 \mathrm{kHz}$; FFT size: 512; window size: 512; window type: Hamming, 50\% overlap. In (e), Fast Fourier Transform (FFT) size: 512; window size: 64. Arrows indicate fish sound sequences (e). 

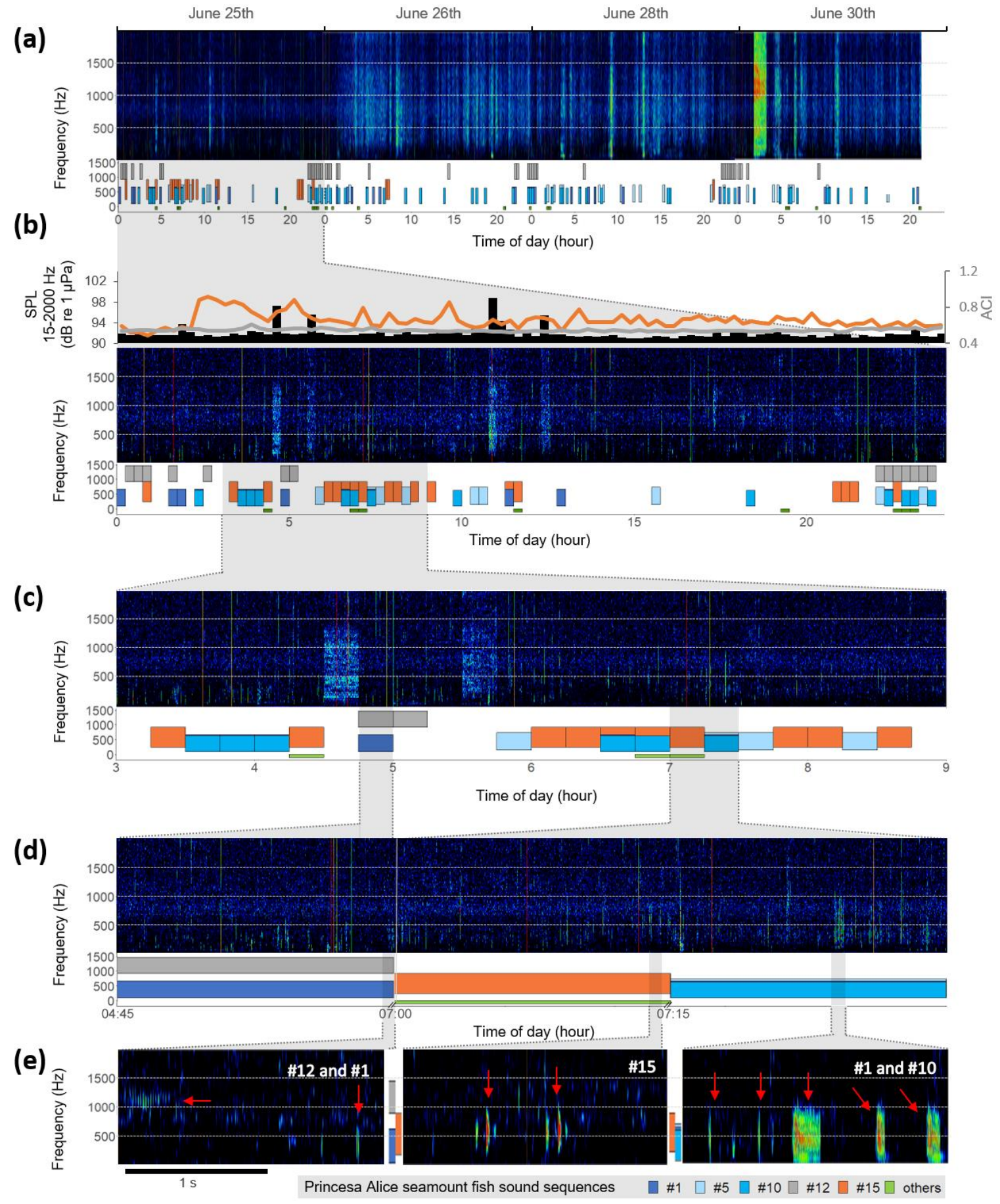

Figure 3. (a) Four-day long-term spectrogram from the Princesa Alice seamount (36 $\mathrm{m}$ deep) with segments expanded to $24 \mathrm{~h} \mathrm{(b)}, 6 \mathrm{~h} \mathrm{(c),270} \mathrm{s} \mathrm{(d)} \mathrm{and} 2 \mathrm{~s}(\mathbf{e})$. Note that the $2 \mathrm{~s}$ spectrograms (e) depict fish sound sequence types (\#1,\#10,\#12,\#15, reported in [23]). Sound acquisition was made $90 \mathrm{~s}$ every $900 \mathrm{~s}$. Under each spectrogram the frequency range occupied by the most common fish sound sequences is represented. In (b), the SPL is presented for a $24 \mathrm{~h}$ period ( 25 June, black bars) for the frequency band 15-2000 Hz, the average SPL considering the 4 days is depicted by the orange line, and the mean $\mathrm{ACI}$ is also presented for the same frequency band by the grey line. Spectrogram settings: Sampling frequency: $8 \mathrm{kHz}$; FFT size: 512; window size: 512; window type: Hamming, 50\%overlap; for the extensions to observe individual sounds, a FFT size of 512 and a window size of 64 were used. Arrows indicates the fish sound sequences (e). 


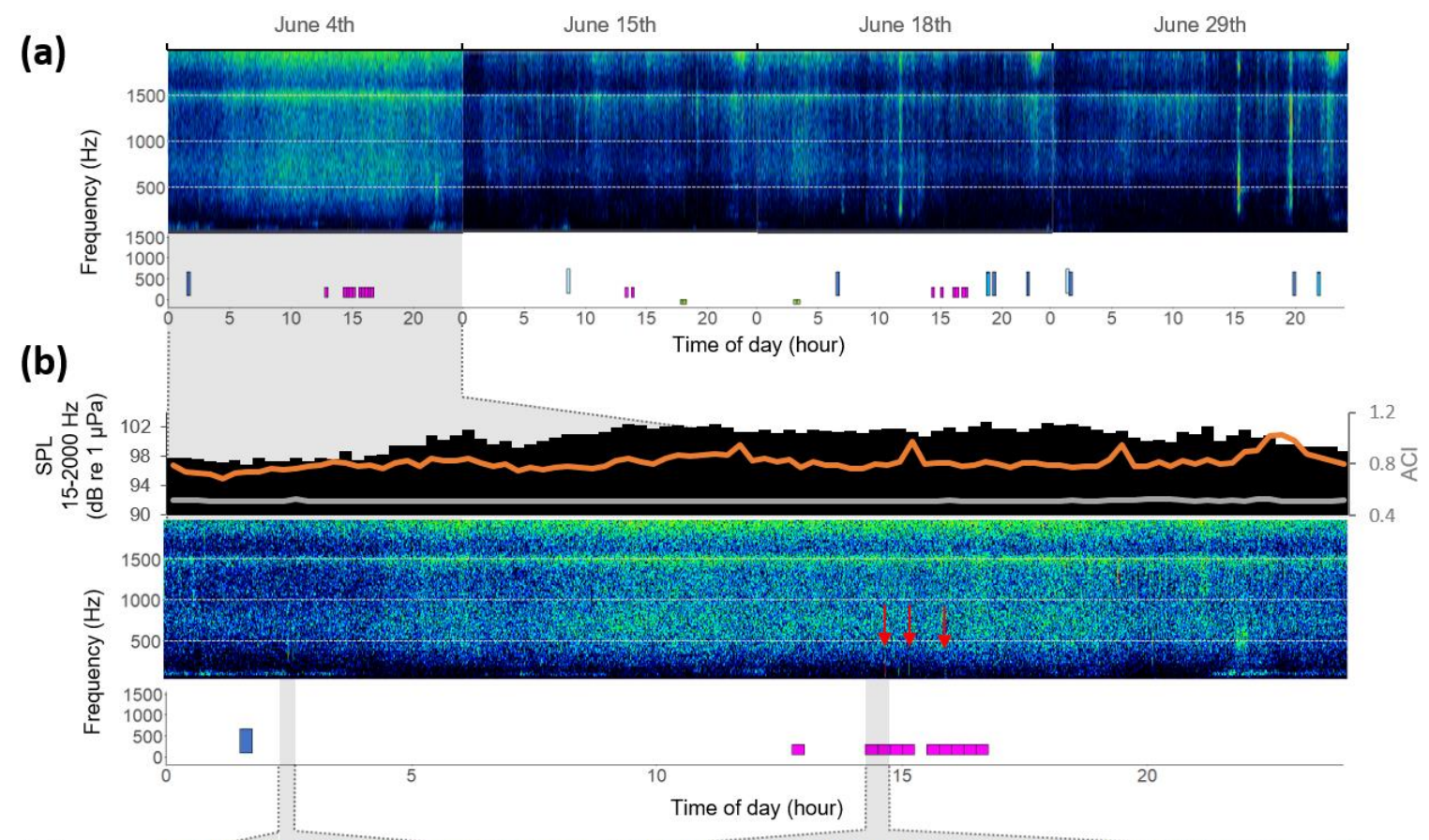

(c)

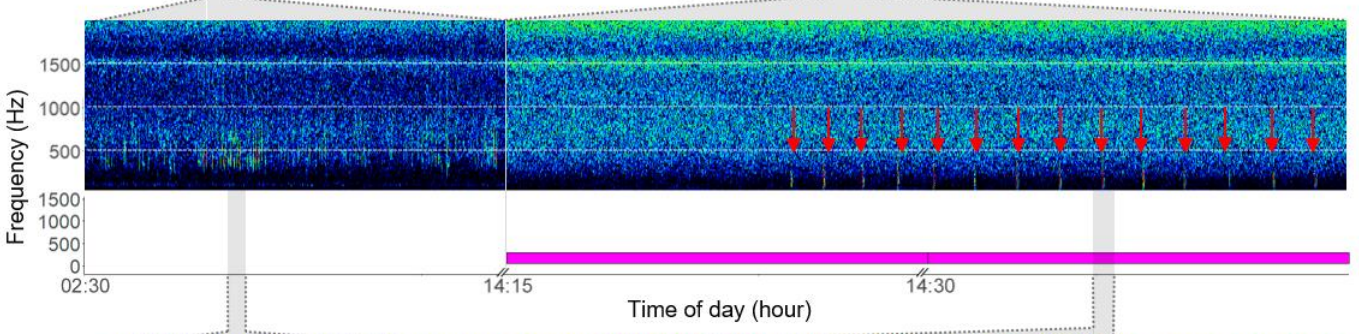

(d)
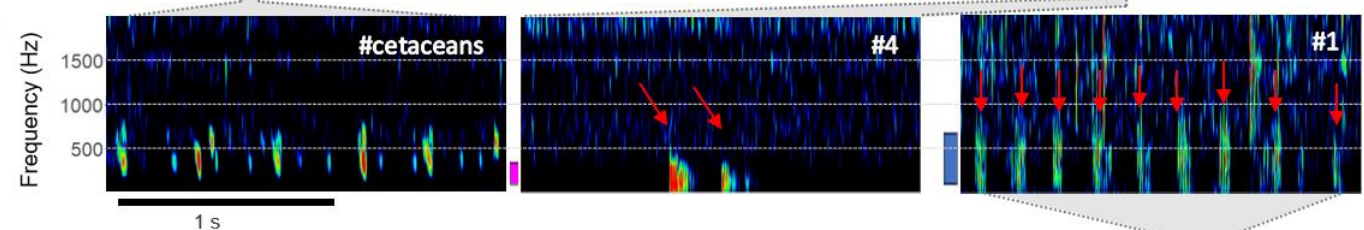

(e)

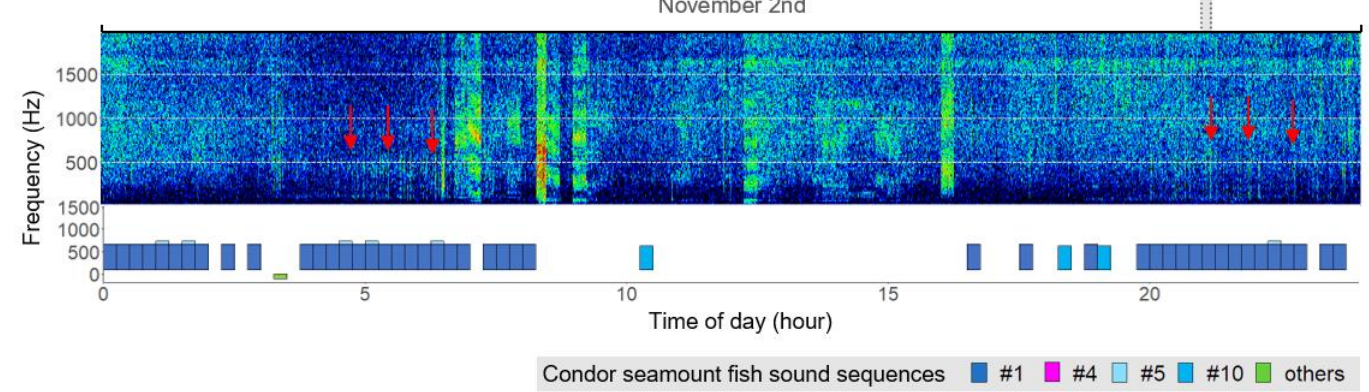

Figure 4. (a) Four-day long-term spectrogram from the Condor seamount (190 m deep) with segments expanded to $24 \mathrm{~h} \mathrm{(b)}, 270 \mathrm{~s}$ (c) and $2 \mathrm{~s}(\mathbf{d})$. Note that the $2 \mathrm{~s}$ spectrograms (d) depict fish sound sequence types (\#1 and \#4 reported in [23]) and some cetacean sounds. Sound acquisition was made 90 s every $900 \mathrm{~s}$. Under each spectrogram the frequency range occupied by the most common fish sound sequences are represented. In (b), the SPL is presented for a $24 \mathrm{~h}$ period (June 4 th - black bars) for the frequency band 15-2000 Hz, the average SPL considering the 4 days is depicted by the orange line, and the mean $\mathrm{ACI}$ is also presented for the same frequency band by the grey line. The bottom panel (e) represent a day in November 2008 with a higher occurrence of sounds. Spectrogram settings: Sampling frequency: $8 \mathrm{kHz}$; FFT size: 512; window size: 512; window type: Hamming, 50\% overlap; for the extensions to observe individual sounds a FFT size of 512 and a window size of 64 were used. Arrows indicates fish sound sequences $(\mathbf{b}, \mathbf{c}, \mathbf{d}, \mathbf{e})$. 
The Spectral Probability Density plots in Figure 5 illustrate the contribution of the different sound sources to soundscapes at the three locations for the selected 4 days in June 2010, depicting the different percentiles (1\%, 5\%, median, 95\%, 99\%) and the Root Mean Square level (RMS). The SPD from Formigas exhibits three peaks, especially for the lower percentiles $(1 \%, 5 \%)$ and the median, which seem to be highly related with the power spectra of the sound sequences \#12 (higher amplitude at about $1300 \mathrm{~Hz}$ ), \#15 (higher amplitude at about $430 \mathrm{~Hz}$ ) and \#50 (higher amplitude at about $250 \mathrm{~Hz}$ ) (Figures 5 and 6). The strongest SPD peak (400-500 Hz) is observed in all percentiles, which may be related with the presence of the sound sequences \#15 near and far from the hydrophone.

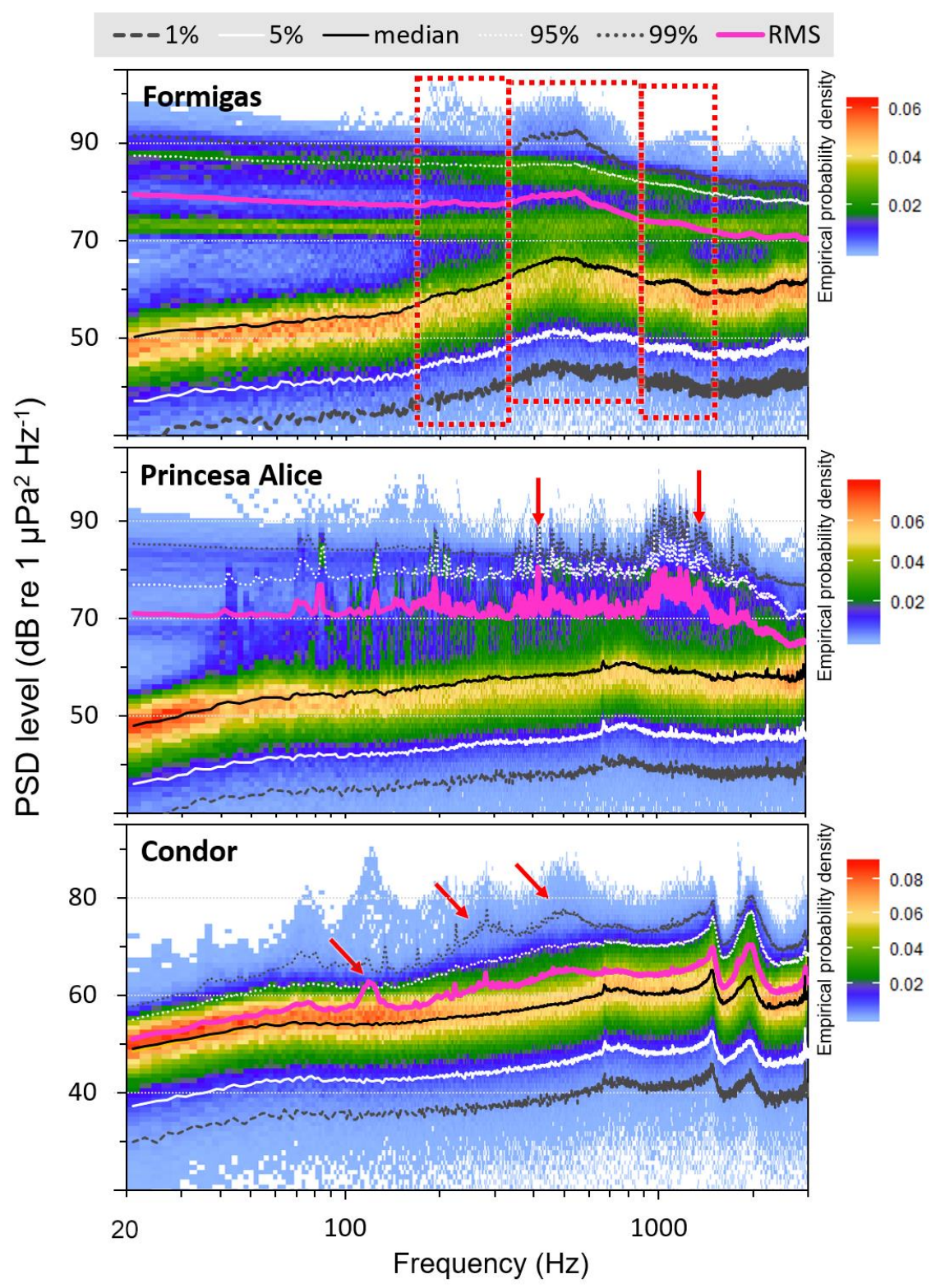

Figure 5. Spectral Probability Density levels (SPDs), percentiles and Root Mean Square (RMS) level of 4 days of recordings from June 2010 for the three seamounts: Formigas, Princesa Alice and Condor. SPDs were produced for each $1 \mathrm{~s}$ time segments using an FFT size of 4096 points. 

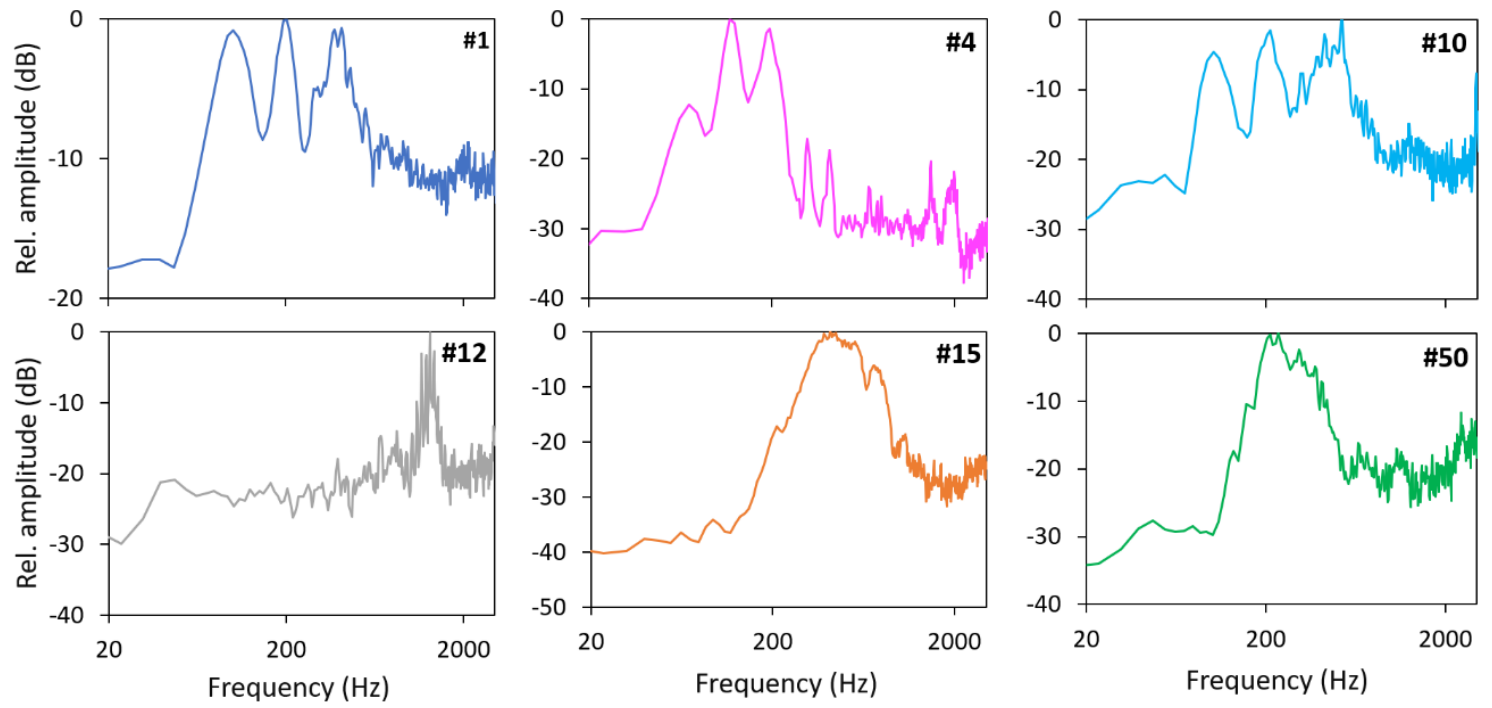

Figure 6. Power spectra for the best example of six common fish sound sequences manually identified from recordings. Spectra settings: sampling frequency: 8 kHz; FFT size: 1024; window type: Hanning, $50 \%$ overlap.

The SPD from Princesa Alice presents the two most pronounced peaks at about $400 \mathrm{~Hz}$ and 1000-1300 Hz, especially at the higher percentiles (95\%, 99\%), which should have a strong influence of anthropogenic noise, such as boat noise. The power spectrum of the sound sequence \#10 (with higher amplitudes at about $200-400 \mathrm{~Hz}$ ) may slightly contribute for the $400 \mathrm{~Hz}$ peak, while the sound sequence \#12 (with higher amplitude at about 1200-1300 Hz) may have a smaller contribution for the peak at around $1200 \mathrm{~Hz}$ (Figures 5 and 6). Higher SPD percentiles (95\%, 99\%) highlight the influence of anthropogenic noise at higher frequencies; those anthropogenic sounds can be clearly recognized in the morning of 30 June (see Figure 3a).

The SPD from Condor present peaks at $127 \mathrm{~Hz}$ (at percentiles: 99\% and RMS), at 200-500 Hz (percentiles: 99\% and RMS) and at higher frequencies $(1500 \mathrm{~Hz}$ and $2000 \mathrm{~Hz})$. Fish sound sequences \#1 (with higher amplitude at about 100-400 Hz), \#4 (with higher amplitude at 100-200 Hz) and cetacean sounds may help to explain the $127 \mathrm{~Hz}$ and $200-500 \mathrm{~Hz}$ peaks. The other peaks may be influenced by the sounds from cetaceans and anthropogenic noise, whose presence was observed in the various frequency ranges.

\section{Discussion}

Fishes are prolific contributors to marine underwater sound around the world and understanding the relation between fish sound patterns and ecosystem health would be a major advance towards using PAM as a major conservation tool [47]. A first step to understand these patterns is to use meaningful data visualization and data reduction methods to relay adequate information on local ecosystems that may vary in the contribution of biological sound sources. Here, we addressed how temporal resolution affects the information gained from common data visualization methods and acoustic metrics like long-term spectrograms, SPD plots, SPL or the ACI when applied to soundscapes with different contributions from vocal fish communities. We show that, despite focusing only on marine seamounts, regarded as biodiversity hotspots, the chosen temporal frame significantly affects the retrievable information on vocal fish communities from the applied methods, depending on the abundance of fish sounds. 
The selected locations are three contrasting habitats with distinct characteristics: Formigas is a shallow seamount, and has been a protected area since 1988 [36]. Princesa Alice, with a similar depth, is an oceanic seamount, and a famous fishing and recreational diving spot without any protection status at the time of the recordings. Condor is the deepest seamount $(190 \mathrm{~m})$ and due to its difficult access is a location that could greatly benefit from being monitored with PAM. Condor has also been covered by a protection status since June 2010 to enable research and monitoring activities [35]. All these particularities should be reflected on the local fish communities and associated biophony. According to Carriço et al. [23,42], acoustic signals produced by fishes on these seamounts can inform us about local biodiversity, presenting similar trends to those obtained with other surveying methods like fishing [42] or visual censuses [48]. Here, we investigated whether graphical representations of soundscapes may inform us about vocal fish communities at these locations.

Formigas presented a notable example of a location where PAM can provide valuable information on the acoustic activity patterns of fish communities, particularly using long-term spectrograms, and SPL and SPD plots. In addition, any of the chosen temporal frames were suitable to illustrate the contribution of fishes to the soundscape. Spectrograms, were useful to reveal a partitioning of fish sounds in frequency and time (Figure 2), clearly indicating that different putative species (possibly associated with different sound sequence types) may vocalize at different periods and exploit different frequency bands. The variation in SPL values was associated with the occurrence of fish sounds observed in the spectrograms. Also, the higher SPL values (higher than those recorded in the other studied locations) are likely associated with the overall stronger biophony at this seamount. This suggests that passive acoustic monitoring associated with long-term soundscape graphical representations are invaluable tools for the soundscape assessment in these habitat types (with a high abundance of vocal fish species likely resulting from a 32-year protection status [36]). Note that higher SPL values may also be influenced by louder sources or reflecting animals being closer to the hydrophone.

In contrast, the Princesa Alice seamount (with no protection status at the time of the recordings) had a lower number of fish sound sequences, and did not exhibit robust patterns with the visualization methods used to inspect the vocal fish community, suggesting that monitoring this habitat with long-term spectrograms, SPL or SPD plots is ineffective. Although some of the sound sequences were similar to Formigas, their lower abundance resulted in less obvious patterns in the spectrograms and lower SPL levels. Only in the expanded spectrograms (270 s and $2 \mathrm{~s}$ ) could fish sounds be visible. Also, fish sounds were only discreetly present in the lowest percentiles $(1 \%, 5 \%$, median) of the SPD.

Condor presented the lowest fish biophony and SPL levels close to those recorded in Princesa Alice. This was observed even in November 2008 (a month with a known high fish vocal activity [41]), where there was a pronounced presence of two fish sounds (\#1 and \#10), with a marked daily pattern (mostly present at dusk, night and dawn) (Figure 4e). The recordings from these two months showed a temporal variability for the same location [42]. However, although the abundance of sounds was much higher in November 2008, it was still below the values found for Formigas. Similar to Princesa Alice, the different visualization methods did not offer robust tools to monitor fish communities. Even if there may be a smaller number of sounds produced by vocal fish species, which may be related with the fact that greater depth accommodates less diversity, an important note to consider is that the hydrophone deployed at Condor was placed at about 8-10 $\mathrm{m}$ above the bottom, likely hindering the detection of low-intensity sounds from vocal benthonic fishes [49]. The propagation distance of the sounds produced by some fish species may vary from a few centimeters to several meters [50-52], which, depending on the species, makes the distance from the emitter to the hydrophone a crucial factor in the efficiency to monitor vocal fish. On the other hand, in Formigas and Princesa Alice, the hydrophone was deployed on the seafloor, allowing better recordings of benthonic species which could have caused additional differences beyond those inherent to the distinct community and habitat type. Consequently, the abundance of fish sounds and the distance of the hydrophone to the source 
seem to be two determinant factors to allow the detection and evaluation of the presence of vocal species in long-term recordings.

The different calling activity among different locations may have been influenced by different factors, such as water depth, food availability, spawning opportunities and protection status, which are determinant for the spatial distribution of the vocal fish species. Although it was not possible to identify any of the source species responsible for the sound sequences found in the seamounts, all the sequences exhibited general characteristics common to fish sounds such as presenting low frequency $(<2 \mathrm{kHz})$, little or no frequency modulation, short duration, and temporal patterns within the range of other reported fish sounds [23,41,53]. For example, the sound sequence \#12 presented many similarities with the sounds recorded in the Mediterranean belonging to the Scorpaena genus [23,54], which has some species present in Azores.

Of the different visualization techniques, long-term spectrograms seem particularly informative to study ecological processes as they allow the observation of a temporal-spectral acoustic structure that may contain relevant ecological information [55]. For example, Parsons et al. [56] note that the separation of the acoustic signals in frequency and time observed in fish choruses [53], following the acoustic niche hypotheses [25], may help to increase the detectability of sounds in the presence of other competing biological or anthropogenic sounds $[57,58]$ that are increasingly present nowadays in the marine soundscapes. This may provide an adaptive advantage to these species, since, by being more effective in their communication, they should increase their reproductive success [59]. Additionally, Kaplan et al. [60] state that the assessment of coral reefs sounds through long-term acoustic recordings enabled the observation of a relationship between the biological sound production and fish density, and coral cover, which reinforces the idea that the acoustic data can be used as an approximation for the presence and abundance of fish species, as well as to inform and bring insights about habitat features $[10,15]$.

The utility of a commonly used acoustic index, the ACI, was also assessed. The ACI proved to be ineffective in reporting the inherent complexity of fish biophony. Although in Formigas the values were higher, in accordance with its high fish biophony, it showed no clear pattern except a slight increase in the index values associated with the presence of some fish sounds at the end of 4 June (Figure 2b), but it was not representative of fish sound patterns in the remaining studied period. In the same way, for the other two places, it was not possible to see any obvious relationship between the ACI and fish biophony. Bohnenstiehl and colleagues only observed an increase of the ACI associated to an increase of fish calling rates when using a finer spectral resolution in the analysis but obtained opposite results when using coarse spectral resolutions [61]. Likewise, Lindseth and Lobel [62] also state that the index may overlook finer details in the presence of one dominant vocalization. Although, the ACI had been successfully applied in several studies in the marine environment $[11,63,64]$, care is still needed when making comparisons between different locations or with other studies, since they are highly dependent on the chosen settings $[12,61]$ and may be driven by differences in biological sources, weather conditions and anthropogenic activities [65].

Is PAM only useful in locations with a very strong fish biophony? Parsons et al. [47] raise the enquiry whether the metrics and techniques used should be environmental or species-specific. We additionally suggest that it is mostly important to adapt the soundscape analysis methods to the level of fish biophony to extract meaningful information. Therefore, the best approach to be used at sites with low fish biophony is to associate short-term spectrograms (e.g., Figure 2d,e, Figure 3d,e and Figure $4 \mathrm{c}, \mathrm{d}$ ) of selected hours of the day and combine them with other techniques like manual annotation (not possible with large data sets) or automatic recognition of fish sounds [66,67], and the use of a set of several acoustic indices and/or other acoustic data reduction methods- on this, see the work of [30]. These additional techniques can be especially useful for data reduction applied to long-term acoustic recordings. Automatic recognition methods enable fast detection of underwater bioacoustic signals produced by marine animals. These methods can use machine learning to find a certain acoustic pattern similar to the sound of interest from a set of various acoustic recordings [68]. 
Using a different approach, acoustic indices characterize the distribution of the acoustic energy in the recordings in a single value and can be used as approximate measures of species abundance and diversity [30,38].

\section{Conclusions}

This study contributes to highlight the usefulness of some currently used graphical representations of acoustic data to study different ecosystems, and how much information they can relay according to the biological sound contribution to the soundscape type and characteristics of the habitat. Here we show that, for locations with a high abundance and diversity of fish sounds, PAM associated with visualization methods for soundscape analysis is a useful tool to assess and monitor fish communities. However, at other locations where sound abundance is lower, the analysis of long-term spectrograms, SPD, SPL or ACI may not be by themselves the best approach. Thus, visualization techniques must be complemented with other methods, such as automatic recognition of fish sounds, [66-69] or with the combined application of several acoustic indices [29,31,47] to avoid missing or underrepresenting some important acoustic sources.

Author Contributions: Conceptualization, M.C.P.A., and P.J.F.; methodology, P.J.F., M.C.P.A., M.V.; software, M.V.; formal analysis M.V., R.C.; investigation, M.A.S., P.A.; resources, M.A.S., P.A., G.M.M.; data curation, R.C., M.V.; Writing-Original draft preparation, R.C.; Writing—Review and Editing, R.C., M.C.P.A., P.J.F., M.V., M.A.S., P.A., G.M.M.; visualization, R.C., M.V.; supervision, M.C.P.A., P.J.F.; project administration, M.S., P.A.; funding acquisition, M.A.S. All authors have read and agreed to the published version of the manuscript.

Funding: Data collection for this study was supported by the Fundação para a Ciência e a Tecnologia (FCT), Azores 2020 Operational Programme and the Fundo Regional da Ciência e Tecnologia (FRCT), through research projects TRACE (PTDC/MAR/74071/2006), MAPCET (M2.1.2/F/012/2011), FCT-Exploratory (IF/00943/2013/CP1199/CT0001), WATCH IT (Acores-01-0145-FEDER-000057), and MISTIC SEAS II (GA11.0661/2017/750679/SUB/ENV.C2), through funds from FEDER, COMPETE, QREN, POPH, ESF, the Portuguese Ministry for Science and Education, and EU-DG/ENV. The Azores 2020 Operational Programme is funded by the community structural funds ERDF and ESF. The RC was funded by the Azorean Regional Fund to Science and Technology-FRCT in the scope of a doctoral grant (M3.1.a/F/070/2015) of the project "Passive acoustic monitoring as a tool to monitor habitat health and vocal fish species of commercial or conservation interest". The MAS was supported through project SUMMER (H2020-EU.3.2.3.1, GA 817806). Funds were also provided by FCT to the strategic projects UID/MAR/04292/2019 to MCPA and RC by MARE, UID/BIA/00329/2019 to PJF by cE3c, and SFRH/BD/115562/2016 to MV.

Acknowledgments: We are grateful to Irma Cascão, Rui Prieto, Jorge Fontes and the skippers and crewmembers that helped with the deployment of the EARs. We thank Irma Cascão and Miriam Romagosa for the assistance with the data. We thank Marta Bolgan for the help to use the Acoustic Complexity Index with the plug-in SoundscapeMeter in the software WaveSurfer.

Conflicts of Interest: The authors declare no conflict of interest. The funders had no role in the design of the study; in the collection, analyses, or interpretation of data; in the writing of the manuscript, or in the decision to publish the results.

\section{References}

1. Mann, D.A.; Lobel, P.S. Propagation of damselfish (Pomacentridae) courtship sounds. J. Acoust. Soc. Am. 1997, 101, 3783-3791. [CrossRef]

2. Buscaino, G.; Filiciotto, F.; Gristina, M.; Bellante, A.; Buffa, G.; Di Stefano, V.; Maccarrone, V.; Tranchida, G.; Buscaino, C.; Mazzola, S. Acoustic behaviour of the European spiny lobster Palinurus elephas. Mar. Ecol. Prog. Ser. 2011, 441, 177-184. [CrossRef]

3. Popper, A.N.; Hawkins, A.D. An overview of fish bioacoustics and the impacts of anthropogenic sounds on fishes. J. Fish Biol. 2019, 94, 692-713. [CrossRef] [PubMed]

4. Popper, A.N.; Fay, R.R.; Platt, C.; Sand, O. Sound detection mechanisms and capabilities of teleost fishes. In Sensory Processing in Aquatic Environments; Collin, S.P., Marshall, N.J., Eds.; Springer: New York, NY, USA, 2003; pp. 1-53. 
5. Cato, D.H.; Noad, M.J.; McCauley, R.D. Passive acoustics as a key to the study of marine animals. In Sounds in the Sea: From Ocean Acoustics to Acoustical Oceanography; Medwin, H., Ed.; Cambridge University Press: Cambridge, UK, 2005; pp. 411-429.

6. McWilliam, J.; Hawkins, A. A comparison of inshore marine soundscapes. J. Exp. Mar. Biol. Ecol. 2013, 446, 166-176. [CrossRef]

7. Kaatz, I.M. Multiple sound producing mechanisms in teleost fishes and hypotheses regarding their behavioural significance. Bioacoustics 2002, 12, 230-233. [CrossRef]

8. Vermeij, M.J.A.; Marhaver, K.L.; Huijbers, C.M.; Nagelkerken, I.; Simpson, S.D. Coral Larvae Move toward Reef Sounds. PLoS ONE 2010, 5, e10660. [CrossRef]

9. Chapuis, L.; Bshary, R. Signalling by the cleaner shrimp Periclimenes longicarpus. Anim. Behav. 2010, 79, 645-647. [CrossRef]

10. Lillis, A.; Eggleston, D.; Bohnenstieh, D. Estuarine soundscapes: Distinct acoustic characteristics of oyster reefs compared to soft-bottom habitats. Mar. Ecol. Prog. Ser. 2014, 505, 1-17. [CrossRef]

11. Harris, S.; Shears, N.; Radford, C. Ecoacoustic indices as proxies for biodiversity on temperate reefs. Methods Ecol. Evol. Br. Ecol. Soc. 2016. [CrossRef]

12. Bolgan, M.; Amorim, M.C.P.; Fonseca, P.J.; Di Iorio, L.; Parmentier, E. Acoustic Complexity of vocal fish communities: A field and controlled validation. Sci. Rep. 2018, 8, 10559. [CrossRef]

13. Miksis-Olds, J.L.; Martin, B.; Tyack, P.L. Exploring the Ocean through Soundscapes. Acoust. Today 2018, 14, $26-34$.

14. Erbe, C.; McCauley, R.; Gavrilov, A. Chapter 31-Characterizing Marine Soundscapes. In The Effects of Noise on Aquatic Life II, Advances in Experimental Medicine and Biology; Popper, A.N., Hawkins, A., Eds.; Springer Science+Business Media: New York, NY, USA, 2013.

15. Bertucci, F.; Parmentier, E.; Lecellier, G.; Hawkins, A.D.; Lecchini, D. Acoustic indices provide information on the status of coral reefs: An example from Moorea Island in the South Pacific. Sci. Rep. 2016, 6, 1-9. [CrossRef] [PubMed]

16. Bolgan, M.; Gervaise, C.; Di Iorio Lossent, J.; Lejeune, P.; Raick, X.; Parmentier, E. Fish biophony in a Mediterranean submarine canyon. J. Acoust. Soc. Am. 2020, 147, 2466. [CrossRef] [PubMed]

17. Luczkovich, J.J.; Mann, D.A.; Rountree, R.A. Passive acoustics as a tool in fisheries science. Trans. Am. Fish. Soc. 2008, 137, 533-541. [CrossRef]

18. Davies, G.E.; Baumgartner, M.F.; Van Parijs, S.M. Long-term passive acoustic recordings track the changing distribution of North Atlantic right whales (Eubalaena glacialis) from 2004 to 2014. Sci. Rep. 2017, 7, 13460. [CrossRef] [PubMed]

19. Caiger, P.E.; Dean, M.J.; DeAngelis, A.I.; Hatch, L.T.; Rice, A.N.; Stanley, J.A.; Tholke, C.; Zemeckis, D.R.; Van Parijs, S.M. A decade of monitoring Atlantic cod Gadus morhua spawning aggregations in Massachusetts Bay using passive acoustics. Mar. Ecol. Prog. Ser. 2020, 635, 89-103. [CrossRef]

20. Rice, A.N.; Soldevilla, M.S.; Quinlan, J.A. Nocturnal patterns in fish chorusing off the coasts of Georgia and eastern Florida. Bull. Mar. Sci. 2017, 93, 2. [CrossRef]

21. Parmentier, E.; Di Iorio, L.; Picciulin, M.; Malavasi, S.; Lagardère, J.-P.; Bertucci, F. Consistency of spatiotemporal sound features supports the use of passive acoustics for long-term monitoring. Anim. Conserv. 2017. [CrossRef]

22. Ricci, S.W.; Eggleston, D.B.; Bohnenstiehl, D.R. Use of passive acoustic monitoring to characterize fish spawning behavior and habitat use within a complex mosaic of estuarine habitats. Bull. Mar. Sci. 2017, 93, 439-453. [CrossRef]

23. Carriço, R.; Silva, M.A.; Menezes, G.M.; Fonseca, P.J.; Amorim, M.C.P. Characterization of the acoustic community of vocal fishes in the Azores. PeerJ 2019, 7, e7772. [CrossRef]

24. Harris, S.A.; Radford, C.A. Marine Soundscape Ecology. Available online: https://pdfs.semanticscholar.org/ 578c/dc57de0179040d652f7deefbabe9d9fe7399.pdf (accessed on 10 April 2020). 
25. Putland, R.L.; Constantine, R.; Radford, C.A. Exploring spatial and temporal trends in the soundscape of an ecologically significant embayment. Sci. Rep. 2017, 7, 5713. [CrossRef]

26. Bertucci, F.; Maratrat, K.; Berthe, C.; Besson, M.; Guerra, A.; Raick, X.; Lerouvreur, F.; Lecchini, D.; Parmentier, E. Local sonic activity reveals potential partitioning in a coral reef fish community. Oecologia 2020. [CrossRef] [PubMed]

27. Wang, Z.-T.; Nowacek, D.P.; Akamatsu, T.; Wang, K.-X.; Liu, J.-C.; Duan, G.-Q.; Cao, H.-J.; Wang, D. Diversity of fish sound types in the Pearl River Estuary, China. Peer] 2017, 5, e3924. [CrossRef] [PubMed]

28. Pieretti, N.; Farina, A.; Morri, D. A new methodology to infer the singing activity of an avian community: The Acoustic Complexity Index (ACI). Ecol. Indic. 2011, 11, 868-873. [CrossRef]

29. Sueur, J.; Farina, A.; Gasc, A.; Pieretti, N.; Pavoine, S. Acoustic Indices for Biodiversity Assessment and Landscape Investigation. Acta Acust. United. Acus. 2014, 100, 772-781. [CrossRef]

30. Phillips, Y.F. Analysis and Visualization of Very-long-duration Acoustic Recordings of the Natural Environment. Ph. D. Thesis, Queensland University of Technology, Brisbane, Australia, 2018.

31. Phillips, Y.F.; Towsey, M.; Roe, P. Revealing the ecological content of long-duration audio-recordings of the environment through clustering and visualization. PLoS ONE 2018, 13, e0193345. [CrossRef] [PubMed]

32. Ruppé, L.; Clément, G.; Herrel, A.; Ballesta, L.; Décamps, T.; Kéver, L.; Parmentier, E. Environmental constraints drive the partitioning of the soundscape in fishes. Proc. Natl. Acad. Sci. USA 2015, 112, 6092-6097. [CrossRef]

33. Haver, S.M.; Klinck, H.; Nieukirk, S.L.; Matsumoto, H.; Dziak, R.P.; Miksis-Olds, J.L. The not-so-silent world: Measuring Arctic, Equatorial, and Antarctic soundscapes in the Atlantic Ocean. Deep Sea Res. Part I Oceanogr. Res. Pap. 2017, 122, 95-104. [CrossRef]

34. Pitcher, T.; Morato, T.; Hart, P.; Clark, M.; Haggan, N.; Santos, R. Seamounts: Ecology, fisheries and conservation. Fish Aquat. Resour. Ser. 2007, 12, 1-476.

35. Giacomello, E.; Menezes, G.M.; Bergstad, O.A. An integrated approach for studying seamounts: CONDOR observatory. Deep Sea Res. Part II Top. Stud. Oceanogr. 2013, 98,1-6. [CrossRef]

36. Christiansen, S.; Tempera, F. The Formigas Bank-A Potential MPA; WWF World Wildlife Fund: Washington, DC, USA, 2010. Available online: http://charlie-gibbs.org/charlie/NEA_Website/Publication/briefings/ FormigasBank.pdf (accessed on 13 June 2020).

37. Lammers, M.; Brainard, R.; Whitlow, W.; Mooney, T.; Wong, K. An Ecological Acoustic Recorder (EAR) for long-term monitoring of biological and anthropogenic sounds on coral reefs and other marine habitats. J. Acoust. Soc. Am. 2008, 123, 1720-1728. [CrossRef] [PubMed]

38. Sousa-Lima, R.S.; Norris, T.F.; Oswald, J.N.; Fernandes, D.P. A Review and Inventory of Fixed Autonomous Recorders for Passive Acoustic Monitoring of Marine Mammals. Aquat. Mamm. 2013, 39, 216-221. [CrossRef]

39. Obrist, M.K.; Pavan, G.; Sueur, J.; Riede, K.; Llusia, D.; Márquez, R. Bioacoustics approaches in biodiversity inventories. Abc Taxa 2010, 8, 68-99.

40. McCauley, R.D.; Cato, D.H. Patterns of fish calling in a nearshore environment in the Great Barrier Reef. Philos. Trans. R. Soc. Lond. B 2000, 355, 1289-1293. [CrossRef] [PubMed]

41. Amorim, M.C.P.; Vasconcelos, R.O.; Marques, J.F.; Almada, F. Seasonal variation of sound production in the Lusitanian toadfish Halobatrachus didactylus. J. Fish Biol. 2006, 69, 1892-1899. [CrossRef]

42. Carriço, R.; Silva, M.A.; Menezes, G.M.; Vieira, M.; Bolgan, M.; Fonseca, P.J.; Amorim, M.C.P. Temporal dynamics in diversity patterns of fish sound production in the Condor seamount (Azores, NE Atlantic). Deep-Sea Res. I (under review).

43. Farina, A.; Lattanzi, E.; Piccioli, L.; Pieretti, N. The SoundscapeMeter. Available online: http://www.iinsteco. org/research-and-technology.php (accessed on 10 April 2020).

44. Sueur, J.; Pavoine, S.; Hamerlynck, O.; Duvail, S. Rapid acoustic survey for biodiversity appraisal. PLoS ONE 2008, 3, e4065. [CrossRef]

45. R Core Team. R: A Language and Environment for Statistical Computing; R Foundation for Statistical Computing: Vienna, Austria, 2018. Available online: https://www.R-project.org/ (accessed on 14 April 2020).

46. Merchant, N.D.; Fristrup, K.M.; Johnson, M.P.; Tyack, P.L.; Witt, M.J.; Blondel, P. Measuring acoustic habitats. Methods Ecol. Evol. 2015, 6, 257-265. [CrossRef] 
47. Parsons, M.; Erbe, C.; McCauley, R.; McWilliam, J.; Marley, S.; Gavrilov, A.; Parnum, I. Long-term monitoring of soundscapes and deciphering a usable index: Examples of fish choruses from Australia. Acoust. Soc. Am. Proc. Meet. Acoust. 2016, 27, 010023. [CrossRef]

48. Desiderà, E.; Guidetti, P.; Panzalis, P.; Navone, A.; Valentini-Poirrier, C.A.; Boissery, P.; Gervaise, C.; Di Iorio, L. Acoustic fish communities: Sound diversity of rocky habitats reflects fish species diversity. Mar. Ecol. Prog. Ser. 2019, 608, 183-197. [CrossRef]

49. Kaatz, I.M.; Rice, A.N.; Loble, P.S. How Fishes Use Sound: Quiet to Loud and Simple to Complex Signaling. Ref. Model Life Sci. 2017, 1-12. [CrossRef]

50. Parsons, M.J.; McCauley, R.D.; Mackie, M.C.; Siwabessy, P.J.; Duncan, A.J. In situ source levels of mulloway (Argyrosomus japonicus) calls. J. Acoust. Soc. Am. 2012, 132, 3559-3568. [CrossRef] [PubMed]

51. Radford, C.A.; Ghazali, S.; Jeffs, A.G.; Montgomery, J.C. Vocalisations of the bigeye Pempheris adspersa: Characteristics, source level and active space. J. Exp. Biol. 2015, 218, 940-948. [CrossRef] [PubMed]

52. Amorim, M.C.P.; Vasconcelos, R.O.; Bolgan, M.; Pedroso, S.S.; Fonseca, P.J. Acoustic communication in marine shallow waters: Testing the acoustic adaptive hypothesis in sand gobies. J. Exp. Biol. 2018, 16, 221. [CrossRef]

53. Parsons, M.J.; Salgado-Kent, C.P.; Marley, S.A.; Gavrilov, A.N.; McCauley, R.D. Characterizing diversity and variation in fish choruses in Darwin Harbour. ICES J. Mar. Sci. 2016, 73, 2058-2074. [CrossRef]

54. Bolgan, M.; Soularde, J.; Di Iorio, L.; Gervaise, C.; Lejeune, P.; Gobert, S.; Parmentier, E. Sea chordophones make the mysterious / Kwa/ sound: Identification of the emitter of the dominant fish sound in Mediterranean seagrass meadows. J. Exp. Biol. 2019, 222. [CrossRef]

55. Sankupellay, M.; Towsey, M.; Truskinger, A.; Roe, P. Visual fingerprints of the acoustic environment. The use of acoustic indices to characterize natural habitats. In 2015 Big Data Visual Analytics (BDVA), Hobart, TAS, Australia, 22-25 September 2015; IEEE: Piscataway, NJ, USA, 2015.

56. Parsons, M.J.; Salgado Kent, C.P.; Recalde-Salas, A.; McCauley, R.D. Fish choruses off Port Hedland, Western Australia. Bioacoustics 2016, 26, 135-152. [CrossRef]

57. Stonea, E. Separating the noise from the noise: A finding in support of the 'niche hypothesis', that birds are influenced by human-induced noise in natural habitats. Anthroös 2000, 13, 225-231. [CrossRef]

58. Krause, B. Wild Soundscapes: Discovering the Voice of the Natural World; Wilderness Press: New Haven, CT, USA, 2002; p. 168.

59. Vasconcelos, R.; Carriço, R.; Ramos, A.; Modesto, T.; Fonseca, P.J.; Amorim, C. Vocal behaviour predicts reproductive success in a teleost fish. Behav. Ecol. 2012, 23, 375-383. [CrossRef]

60. Kaplan, M.B.; Mooney, T.A.; Partan, J.; Solow, A.R. Coral reef species assemblages are associated with ambient soundscapes. Mar. Ecol. Prog. Ser. 2015, 533, 93-107. [CrossRef]

61. Bohnenstiehl, D.R.; Lyon, R.P.; Caretti, O.N.; Ricci, S.W.; Eggleston, D.B. Investigating the utility of ecoacoustic metrics in marine soundscapes. J. Ecoacoust. 2018, 2, R1156L. [CrossRef]

62. Lindseth, A.V.; Lobel, P.S. Underwater Soundscape Monitoring and Fish Bioacoustics: A Review. Fishes 2018, 3, 36. [CrossRef]

63. Belghith, E.H.; Rioult, F.; Bouzidi, M. Acoustic Diversity Classifier for Automated Marine Big Data Analysis. In Proceedings of the IEEE 30th International Conference on Tools with Artificial Intelligence (ICTAI), Volos, Greece, 5-7 November 2018.

64. Davies, B.F.R.; Attrill, M.J.; Holmes, L.; Rees, A.; Witt, M.J.; Sheehan, E.V. Acoustic Complexity Index to assess benthic biodiversity of a partially protected area in the southwest of the UK. Ecol. Indic. 2020, 111, 106019. [CrossRef]

65. Haver, S.M.; Fournet, M.E.H.; Dziak, R.P.; Gabriele, C.; Gedamke, J.; Hatch, L.T.; Haxel, J.; Heppell, S.A.; McKenna, M.F.; Mellinger, M.K.; et al. Comparing the Underwater Soundscapes of Four U.S. National Parks and Marine Sanctuaries. Front. Mar. Sci. 2019, 6, 500. [CrossRef]

66. Malfante, M.; Mars, J.I.; Dalla Mura, M.; Gervaise, C. Automatic fish sounds classification. J. Acoust. Soc. Am. 2018, 143, 2834-2846. [CrossRef] [PubMed]

67. Vieira, M.; Fonseca, P.J.; Amorim, M.C.P.; Teixeira, C.J.C. Call recognition and individual identification of fish vocalizations based on automatic speech recognition: An example with the Lusitanian toadfish. J. Acoust. Soc. Am. 2015, 138, 3941-3950. [CrossRef] 
68. Vieira, M.; Pereira, B.P.; Pousão-Ferreira, P.; Fonseca, P.J.; Amorim, M.C.P. Seasonal variation of captive meagre acoustic signalling: A manual and automatic recognition approach. Fishes 2019, 4, 28. [CrossRef]

69. Monczak, A.; Ji, Y.; Soueidan, J.; Montie, E.W. Automatic detection, classification, and quantification of sciaenid fish calls in an estuarine soundscape in the Southeast United States. PLoS ONE 2019, 14, e0209914. [CrossRef] 